\title{
Methane Hydrate Distribution from Prolonged and Repeated Formation in Natural and Compacted Sand Samples: X-Ray CT Observations
}

\author{
Emily V. L. Rees, ${ }^{1}$ Timothy J. Kneafsey, ${ }^{1}$ and Yongkoo Seol ${ }^{2}$ \\ ${ }^{1}$ Earth Sciences Division, Lawrence Berkeley National Laboratory, 1 Cyclotron Road, Berkeley, CA 94720, USA \\ ${ }^{2}$ Office of Research and Development, National Energy Technology Laboratory, 626 Cochrans Mill Road, P.O. Box 10940, Pittsburgh, \\ PA 15236, USA \\ Correspondence should be addressed to Emily V. L. Rees, evrees@lbl.gov
}

Received 16 June 2011; Revised 12 August 2011; Accepted 13 August 2011

Academic Editor: Xuewei Liu

Copyright (C) 2011 Emily V. L. Rees et al. This is an open access article distributed under the Creative Commons Attribution License, which permits unrestricted use, distribution, and reproduction in any medium, provided the original work is properly cited.

\begin{abstract}
To study physical properties of methane gas hydrate-bearing sediments, it is necessary to synthesize laboratory samples due to the limited availability of cores from natural deposits. X-ray computed tomography (CT) and other observations have shown gas hydrate to occur in a number of morphologies over a variety of sediment types. To aid in understanding formation and growth patterns of hydrate in sediments, methane hydrate was repeatedly formed in laboratory-packed sand samples and in a natural sediment core from the Mount Elbert Stratigraphic Test Well. CT scanning was performed during hydrate formation and decomposition steps, and periodically while the hydrate samples remained under stable conditions for up to 60 days. The investigation revealed the impact of water saturation on location and morphology of hydrate in both laboratory and natural sediments during repeated hydrate formations. Significant redistribution of hydrate and water in the samples was observed over both the short and long term.
\end{abstract}

\section{Introduction}

Gas hydrates (herein called "hydrate" or "hydrates") are nonstoichiometric inclusion compounds formed from a network of hydrogen bonded water molecules encapsulating small gas molecules [1]. Hydrates typically form at high pressures and low temperatures in the presence of water and the hydrateforming compound (e.g., methane, ethane, propane, or carbon dioxide). When formed naturally in sediments, hydrates strongly affect the sediment's mechanical, geophysical, and hydrologic behavior [2]. Methane hydrate has been observed in nature in a wide variety of sediment types, in accumulations ranging from veins and massive nodules of hydrate [36] to dispersed and disseminated hydrate in the pore space of sediments [7-10]. There are numerous hypotheses as to the control of gas hydrate formation in sediments and whether they will form as a pore filling or cementing component of the sediment $[5,11,12]$ or as a grain displacing component resulting in veins, nodules, and layers [13]. Hydrate distributions in natural sediments are attributed to variations in chemistry, lithology, local tectonic activity, and nature of the gas supply in a hydrate-bearing region [1].

Hydrate redistribution in porous media following initial hydrate formation has been observed at the grain scale in a number of visualization experiments [14-16]. This reconfiguration of hydrate crystal shape was typically observed over relatively short timescales (up to several days); however, changes in hydrate distribution over several weeks have not been examined before. The observations from such tests as those conducted by Katsuki et al. [15, 16] and Tohidi et al. [14] are important because changes in hydrate distribution in a sample (e.g., by dissociating at one location and reforming at another) will result in changes in the physical properties of the sediment. Observations of longterm hydrate redistribution under stable conditions are also 
important for understanding natural gas hydrate deposits and how they may change over time.

Repeated hydrate formation has often been reported to yield a "memory effect." This is a phenomenon whereby water molecules retain a "memory" of their previous clathrate structure after dissociation at moderate temperatures. This retention of structure means that hydrate crystals can nucleate more easily from the same water body than when it was originally formed [1]. There have been numerous investigations into the memory effect of gas hydrates [17-23], most of which focus on the changes in the induction time for hydrate reformation after a dissociation event. Evidence from such experiments shows that the induction time for hydrate nucleation reduces significantly if the components have been used to make hydrate previously. There are, however, limitations on the persistence of the memory effect, related to the decomposition state of the previous hydrate and how long the components have been out of the stability zone. The general consensus is that the memory effect can be removed from a system by keeping the system out of the stability zone for longer than 24 hours or by heating the system to a temperature sufficiently above the stability zone for a given pressure [1]. To date, the hydrate memory effect has not been observed directly in sedimenthosted gas hydrate systems nor investigated with regard to its control on the location of hydrate nucleation in a porous media during reformation events.

To understand the formation and growth patterns of methane hydrate in natural sediments, a number of experiments have been performed using a core sample from the Mount Elbert Stratigraphic Test Well located in the Alaskan permafrost. In addition, hydrates were also formed in packed sand samples to allow comparison of hydrate formation in natural and reformed sediments. The aim of the experiments on the two sediment samples was to observe repeated hydrate formation and dissociation using X-ray computed tomography (CT) scanning, investigating the evolving distribution patterns of methane hydrate and also the behavior of hydrate during prolonged time inside the hydrate stability zone. The tests also provided a unique opportunity to investigate whether the memory effect can control the location of hydrate within sediments.

\section{Experimental Methods}

\subsection{Mount Elbert Core}

2.1.1. Sample Origin. The natural sediment used in the test sequence was recovered from the BPXA-DOE-USGS Mount Elbert Gas Hydrate Stratigraphic Test Well. The Mount Elbert well is located in the Milne Point oil field, on the north slope of the Brooks Range in Northern Alaska. The core used in this series of tests came from $660 \mathrm{~m}$ below surface level, part of Unit "C" of the reservoirs sands prevalent in the Milne Point region (Sample HYPV3 in Kneafsey et al. [24]). Descriptions of the geology and hydrate in this permafrost region can be found in Boswell et al. [25], Collett et al. [26], and Rose et al. [27].
2.1.2. Sample Preparation and CT Scanning. After collection, the hydrate-bearing sample was placed in a pressure vessel and pressurized with methane to maintain hydrate stability. The vessel was stored under pressure outdoors in the arctic winter and later moved to a freezer. Prior to shipment, the pressure vessel was rapidly vented and the sample was removed and placed in liquid nitrogen (LN: normal boiling point $-196^{\circ} \mathrm{C}$ ). Once received at the laboratory, the core was removed from LN and the ends of the core were rapidly cut flat. A belt sander was used to remove the outer layer of the sample in many steps, with sequential cooling by submersion in LN to keep the sample cold. Similarly, holes were drilled in the ends of the sample to accommodate thermocouples.

The core sample was encased in a custom-manufactured nitrile butadiene rubber sleeve. Poly-vinyl chloride caps were placed on the ends of the sample inside the sleeve and secured with wire to ensure a snug fit. Thermocouples were inserted into the sample from each end through the end caps to obtain temperature readings from locations inside the sample. A thermocouple was attached to the outside of the rubber sleeve to monitor confining fluid temperature. The core was then placed inside the pressure vessel, and confining pressure was applied.

The pressure vessel used was an X-ray transparent $8.9 \mathrm{~cm}$ outside diameter aluminum tube with threaded stainless steel end caps (Figure 1). The inlet port to the pressure vessel was connected to a high-pressure syringe pump (Teledyne Isco, Lincoln, Neb) and a fixed-volume methane bottle. The outlet of the sample was connected to another high-pressure syringe pump and could also be vented to the atmosphere. Pore pressure in the core was measured at both the inlet and outlet ports. In addition to the thermocouples inside the sample and in the confining fluid, temperature measurements were also made at the methane bottle. Temperature in the system was controlled by flowing temperature-controlled water/propylene glycol through a fluid jacket over the outside of the pressure vessel. Once the pressure cell/fluid jacket assembly was fully connected, it was placed on the CT scanner bed and insulated.

CT scanning was performed using a modified Siemens Somatom HiQ medical X-ray CT scanner. The X-ray CT scanning produced axial $(x-y)$ cross-sections through the cylindrical vessel that could then be assembled to give a three-dimensional volume. Slice thickness was $3 \mathrm{~mm}$, and 54 slices were needed to cover the length of the sample (Figure 2). Resolution of each scan resulted in voxel dimensions of $195 \mu \mathrm{m} \times 195 \mu \mathrm{m} \times 3000 \mu \mathrm{m}(x-y-z)$. The CT scanner was calibrated with known standards (air, water, Lucite, glass, nylon, and aluminum) in order to convert X-ray attenuation data into density.

Prior to the tests described here, the original natural hydrate in the sample had been dissociated by depressurization (the results of this dissociation are described in Kneafsey and Moridis [28]). Following the depressurization, the sample was CT scanned to obtain a baseline for later comparison. The initial scan showed the core to have two distinct regions with different densities (Figure 2). The left $70 \mathrm{~mm}$ of the core in Figure 2 (Part A) has a lower average density than the remaining $92 \mathrm{~mm}$ (Part B). Initial water 


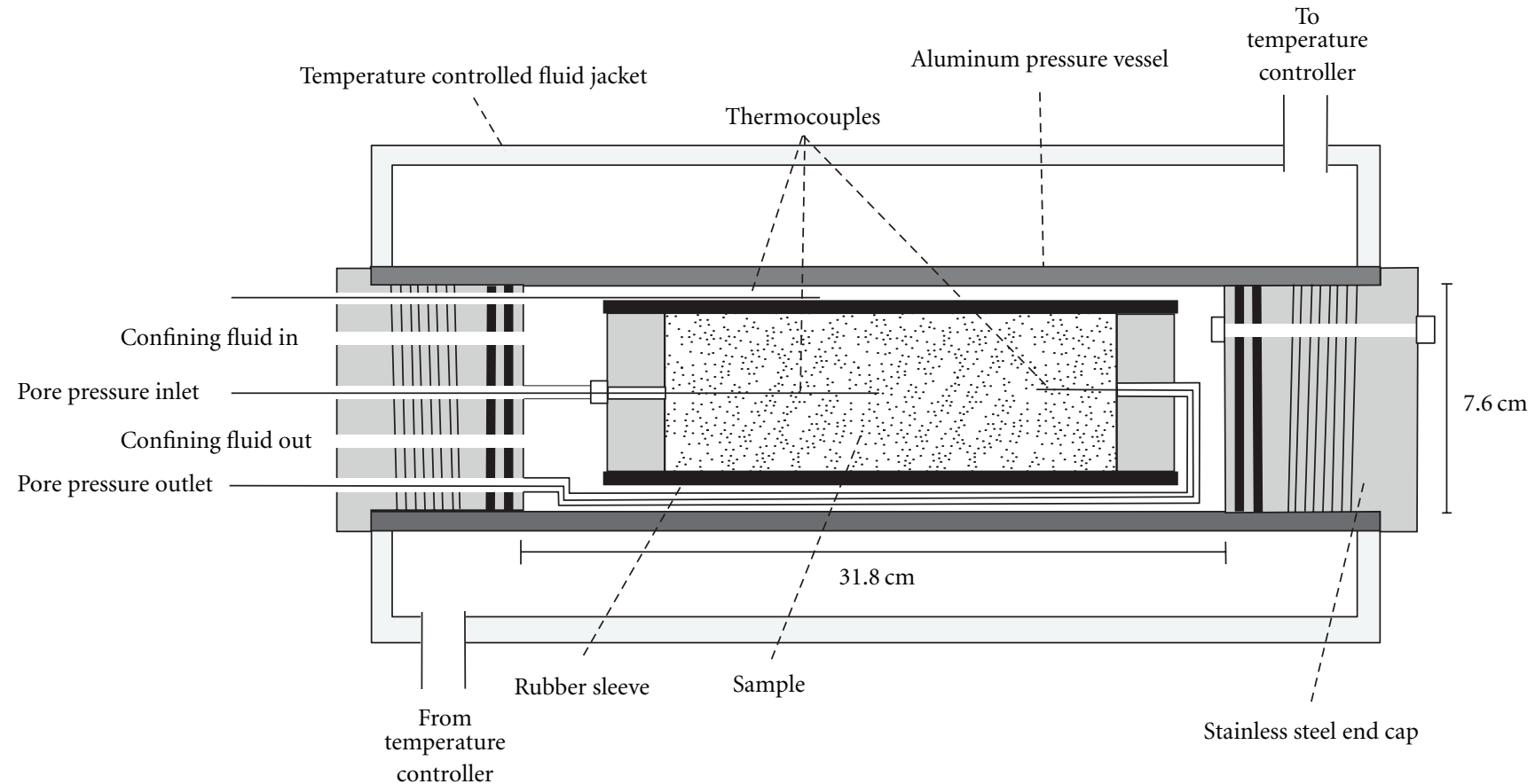

Figure 1: Schematic of the pressure vessel used in the Mount Elbert core tests.
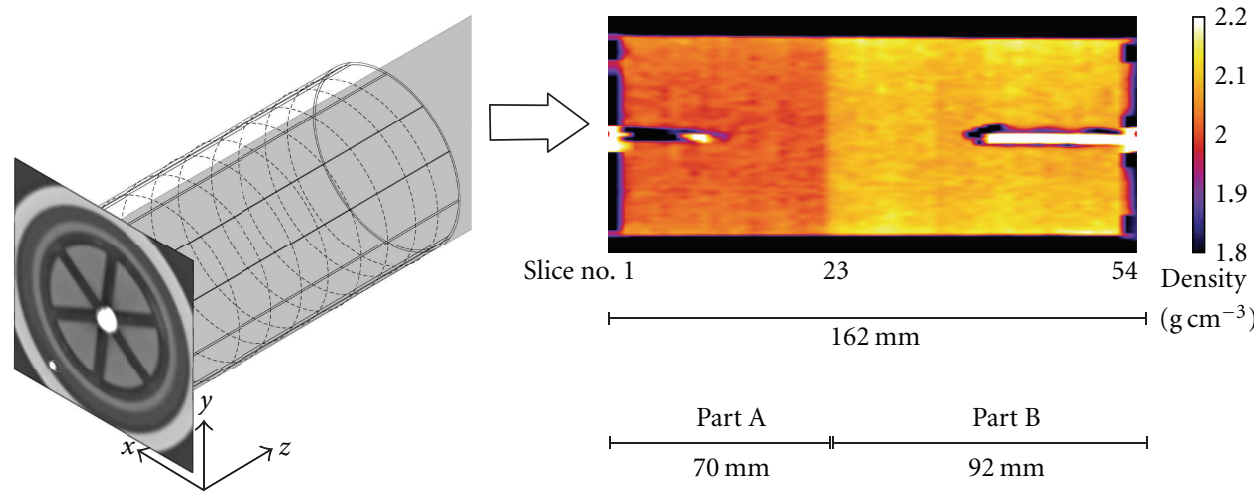

FIGURE 2: CT scanning image presentation for Mount Elbert core section. $54 x-y$ slices are obtained from the scanning process which are $3 \mathrm{~mm}$ deep in the $z$ direction (left). It takes 2.7 seconds to scan each slice, with an additional 10 -second processing time per slice. The 54 slices are reconstructed to produce a $y$ - $z$ slice showing the length of the core (right) and calibrated to give density values. Scan shown here is of the Mount Elbert core after original hydrate has been dissociated, but before laboratory hydrate formation. Parts A and B of the core are indicated.

saturations of each section of the core were also slightly different: Part A had an initial water saturation of 0.59 , whereas Part B had an initial saturation of 0.75 . Water saturations were calculated from calibrated CT scans of the core by comparing density values from the core in a fully water saturated state and a fully dry state. The calculated porosities of Parts A and B based on CT images are 0.29 and 0.28 , respectively. Grain size analysis (Figure 3 ) shows Part A to have a larger average grain size than Part B. This analysis also showed that the average grain size was larger than $10 \mu \mathrm{m}$ for all sediment particles, indicating that the equilibrium conditions for methane hydrate would not be significantly shifted due to pore size inhibition [29]. In addition, XRD analysis shows the mineral content of each part of the core to be similar, with the largest difference being a slightly larger amount of kaolinite in Part A than Part B.

2.1.3. Test Sequence. The test sequence consisted of two phases, each with two tests. In the first phase, the aim was to examine changes in the distribution of methane hydrate in the Mount Elbert core during repeated formation of the hydrate after only a couple of days in the stability zone. Prior to this first test, the Mount Elbert core had been out of the hydrate stability zone for over $24 \mathrm{hrs}$. The first hydrate formation (Test ME1.1) was initiated by increasing the pore pressure to $4.4 \mathrm{MPa}$ (confining pressure to $5.4 \mathrm{MPa}$ ). Hydrate 
TABLE 1: Summary of tests conducted on the Mount Elbert core.

\begin{tabular}{lccccccc}
\hline $\begin{array}{l}\text { Sample phase } \\
\text { no. }\end{array}$ & Test no. & $\begin{array}{c}\text { Formation } \\
\text { method }\end{array}$ & $\begin{array}{c}\text { Pressure start } \\
(\mathrm{MPa})\end{array}$ & $\begin{array}{c}\text { Pressure end } \\
(\mathrm{MPa})\end{array}$ & $\begin{array}{c}\text { Temp } \\
\left({ }^{\circ} \mathrm{C}\right)\end{array}$ & $\begin{array}{c}\text { Time in } \\
\text { hydrate } \\
\text { stability zone }\end{array}$ & $\begin{array}{c}\text { Time to } \\
\text { hydrate } \\
\text { formation }\end{array}$ \\
\hline 1 & ME1.1 & Pressurization & $\begin{array}{c}4.36 \\
*(5)\end{array}$ & $\begin{array}{c}4.14 \\
*(4.6) \\
\text { saturation }\end{array}$ & 3.34 & 2 days & 13 minutes \\
& ME1.2 & Cooling & $\begin{array}{c}4.41 \\
*(5.2)\end{array}$ & $\begin{array}{c}4.16 \\
*(4.6)\end{array}$ & 3.50 & 3 days & 95 minutes \\
\hline
\end{tabular}

${ }^{*}$ Equilibrium temperature for methane hydrate at given pressure $\left({ }^{\circ} \mathrm{C}\right)$.

*a A power failure temporarily stopped data logger.

*b Estimated from CT scans.

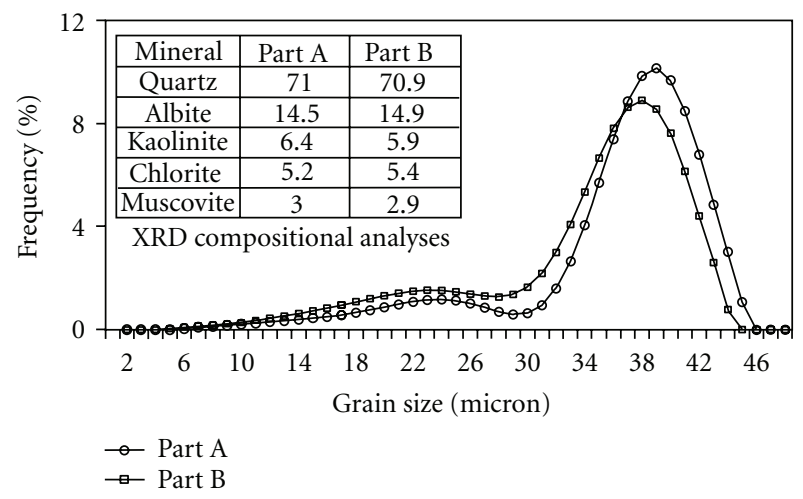

FIgUre 3: Grain-size and XRD analysis for Parts A and B of the Mount Elbert core.

formation began after 13 minutes in the stability zone, marked by an increase in temperature inside the sample. Temperature returned to the set value after $\sim 15$ hours, and hydrate formation was assumed to be complete. The sample was kept in the hydrate stability zone for 2 days before dissociation by increasing the temperature to $10^{\circ} \mathrm{C}$. The sample was then held out of the stability field for another 24 hours before hydrate was reformed by decreasing the temperature to $4^{\circ} \mathrm{C}$ (Test ME1.2). Once inside the stability zone, hydrate formation did not occur for 80 minutes, with temperature and pressure stabilizing after 11 hours. The sample was held in the stability zone for 3 days before dissociation by allowing temperatures and pressures to be equilibrated to ambient conditions.

The second phase of the Mount Elbert core test sequence aimed to maintain hydrate in the core under stable conditions for extended periods of time. Hydrate was first made via pressurization at a cool temperature. Initially, the temperature of the core was lowered from laboratory ambient temperature to $4^{\circ} \mathrm{C}$, with the pore pressure of the system at $2.9 \mathrm{MPa}$ (confining fluid pressure at $4 \mathrm{MPa}$ ). These initial conditions were outside the methane hydrate stability zone. Hydrate formation was initiated by increasing the pore pressure to $4.8 \mathrm{MPa}$ (confining pressure $5.5 \mathrm{MPa}$ ). Hydrate formation began after only 9 minutes inside the stability zone, indicated by an increase in internal temperature of more than $1^{\circ} \mathrm{C}$. After 10 hours, the temperature inside the core returned to the applied temperature $\left(\sim 4^{\circ} \mathrm{C}\right)$, and hydrate formation was considered complete. The core sample remained in the hydrate stability zone for 60 days, during which pressure and temperature were monitored and X-ray CT scans were conducted at intervals of 3 to 10 days (Test ME2.1).

After $\sim 60$ days, the hydrate was dissociated. The pressure inside the vessel remained at $\sim 4.8 \mathrm{MPa}$, since the produced methane vented to a large, pressurized bottle. These conditions are outside of the stability zone for methane hydrate. After several days, the temperature of the system returned to $4^{\circ} \mathrm{C}$, thereby reforming methane gas hydrate in the core via cooling. X-ray CT scanning revealed that hydrate had formed inside the core, and the sample was allowed to remain under hydrate stable conditions for 41 days for continued observation (Test ME2.2). Table 1 gives a summary of the tests in both phases of the testing sequence.

2.1.4. Determination of Hydrate Saturation. During each test the system remained isolated so that the amount of methane consumed by hydrate formation could be calculated from the pressure drop inside the sample and methane bottle. Knowing the temperature of the bottle and sample, the measured pressure drop could be converted to moles of methane consumed by hydrate formation, assuming a constant water to methane molecular ratio of 6 and the methane hydrate density to be $0.917 \mathrm{~g} \mathrm{~cm}^{-3}$ [1]. This measurement gave a bulk hydrate volume for the whole core (Table 1). The porosity was computed using CT scans from the water saturated and dry conditions obtained after the hydrate formation tests. The amount of water in the samples was determined by comparing the $\mathrm{CT}$ scans prior to a test to the CT scans of the samples when water saturated and was dry (obtained after the test). Comparing the predicted number of moles of methane to be consumed by the all of the water present with the measured methane consumption yielded a $70 \%$ conversion of water to methane hydrate.

The spatial distribution of hydrate saturation was calculated through analysis of the CT data combined with 
the mass balance [30]. Part B had a higher average hydrate saturation by $\sim 10 \%$ over Part A, corresponding to the varying initial water saturations, and irregular hydrate distribution (described in more detail in Section 3 ).

2.2. Packed Sand Sample. A predetermined volume of water and fine silica sand (F-110: 99.8\% silica, rounded to subangular grains, $120 \mu \mathrm{m}$ average grain size, used as received [31]) was mixed thoroughly in a sealed container. The volume of water added was calculated to produce the desired water saturation (26 and 37\%) once the sample was packed. The sand and water mixture was kept at room conditions for 12 hours to allow water distribution equilibration before being remixed and packed into a $19.8 \mathrm{~cm}$ long rubber sleeve having an outside diameter of $5.1 \mathrm{~cm}$. The packed rubber sleeve was then placed in a pressure vessel, allowing the application of triaxial confining pressure. Thermocouples at both ends were inserted into the sand pack to monitor temperature. The pressure vessel was enclosed with a water jacket that provided constant temperature conditions over the course of the experiments. Methane hydrate was formed in the sand by raising pore methane gas pressure to $8.3 \mathrm{MPa}$ (confining pressure to $10.3 \mathrm{MPa}$ ), while the system was maintained at $8^{\circ} \mathrm{C}$. The sand sample was continuously monitored for hydrate formation as in the Mount Elbert core tests, using pressure and temperature data and X-ray CT scans. Initiation of hydrate formation was detected by declining pressure and rising temperature inside the sand core.

Experiments were performed to observe hydrate distribution during formation and dissociation within two sand packs (SP1 and SP2). The first tests examined the impact of differing time periods between the end of dissociation for preexisting hydrate and the start of new hydrate formation (Tests SP1). The time periods were varied from 19 hours to 48 hours. The second tests with SP2 were performed to check the repeatability of hydrate distribution patterns (Tests SP2). The time gap between the first dissociation and the second formation was $15.3 \mathrm{hrs}$. SP1 and SP2 had similar initial water saturations (37\% and $26 \%$, resp.) and porosity (34\%), which was uniform throughout the cores (Table 2). Hydrate formation and dissociation were induced by controlling pore pressure with a syringe pump. During repetitive formation and dissociation tests (Tests SP1), the gas within the sample was kept in the syringe pump to maintain a constant total volume of methane gas and water. During the second tests on SP2, the core was monitored more often while hydrate formation was occurring, to capture evolution of hydrate distribution during formation.

\section{Results}

3.1. Short-Term Test Results. As described in Section 2.1.3, methane hydrate was formed twice in the Mount Elbert core sample to observe whether the hydrate formation was repeatable and to examine the distribution of the hydrate across the natural sediment (Tests ME1.1 and ME1.2). Similar tests were conducted in a sand pack with four consecutive hydrate formations in the sample, SP1, and
TABLE 2: Measured properties of packed sand cores.

\begin{tabular}{lcc}
\hline Parameter & SP1 & SP2 \\
\hline Cylinder dimensions: & & \\
Diameter, $d(\mathrm{~mm})$ & 51 & 51 \\
Length, $L(\mathrm{~mm})$ & 188 & 188 \\
Pressure $(\mathrm{MPa})$ & 8.3 & 8.3 \\
Temperature $\left({ }^{\circ} \mathrm{C}\right)$ & 8 & 8 \\
Porosity, $\phi$ & 0.34 & 0.34 \\
Initial water saturation, $S_{w}$ & 0.37 & 0.26 \\
$*$ Hydrate saturation, $S_{H}$, & 0.38 & 0.28 \\
\hline
\end{tabular}

${ }^{*} 100 \%$ water-to-hydrate conversion is assumed.

with two more tests on a second sand pack, SP2. Hydrate formation was documented in each experiment by taking periodic CT scans at specific locations in the cores at frequent intervals. Scanning was started once the onset of hydrate formation was detected in the pressure-temperature data for all the tests. Hydrate formation was indicated in the CT scans by an increase in density, which in this case refers to the mass per voxel volume in $\mathrm{g} \mathrm{cm}^{-3}$. Because the voxel size in these scans $(\sim 195 \mu \mathrm{m} \times 195 \mu \mathrm{m} \times 3000 \mu \mathrm{m})$ was larger than the grain size of the core sediment (less than $45 \mu \mathrm{m}$ for the Mount Elbert sample (Figure 3) and $120 \mu \mathrm{m}$ for the sand packs), each voxel contained sand, gas, hydrate (under proper conditions), and water. The increase in mass caused by the inclusion of methane molecules to the hydrate structure resulted in an increase in density of a voxel in a CT scan since the voxel size was large enough to encompass the volume change of water when it formed hydrate.

Hydrate began to form 13 minutes after pressurizing the core in Test ME1.1 (Table 1), but it did not start for 80 minutes after the sample was cooled into the stability zone in Test ME1.2. Figure 4 compares CT scan data at a single location in the Mount Elbert core $(111 \mathrm{~mm}$ from the end) over the duration of both tests. Figure 4(a) shows hydrate developing as several concentrated masses within the sediment early in Test ME1.1. These masses spread outwards as hydrate formation continues to 170 minutes after initial onset. Figure 4(b) shows hydrate formation during Test ME1.2. Even though hydrate formation has started elsewhere in the core (seen by an increase in temperature and drop in pressure), hydrate formation does not occur at location $111 \mathrm{~mm}$ until 80 minutes after initial onset. In contrast to Test ME1.1, it can be seen in Figure 4(b) that hydrate starts forming at the edge of the core, spreading towards the center as formation continues.

In the packed sand sample SP1, hydrate started forming within 60 minutes after application of pressure and temperature $\left(8.3 \mathrm{MPa}\right.$ and $\left.8^{\circ} \mathrm{C}\right)$ in each of the formation events. It was found, however, that hydrate formation initiated faster after hydrate had once been formed in the core. Subsequent hydrate formation began almost instantaneously as the pressure inside the core reached stability conditions, regardless of the time period left between consecutive dissociation and reformation events. Because of this, no relationship could be determined between induction time and the time 


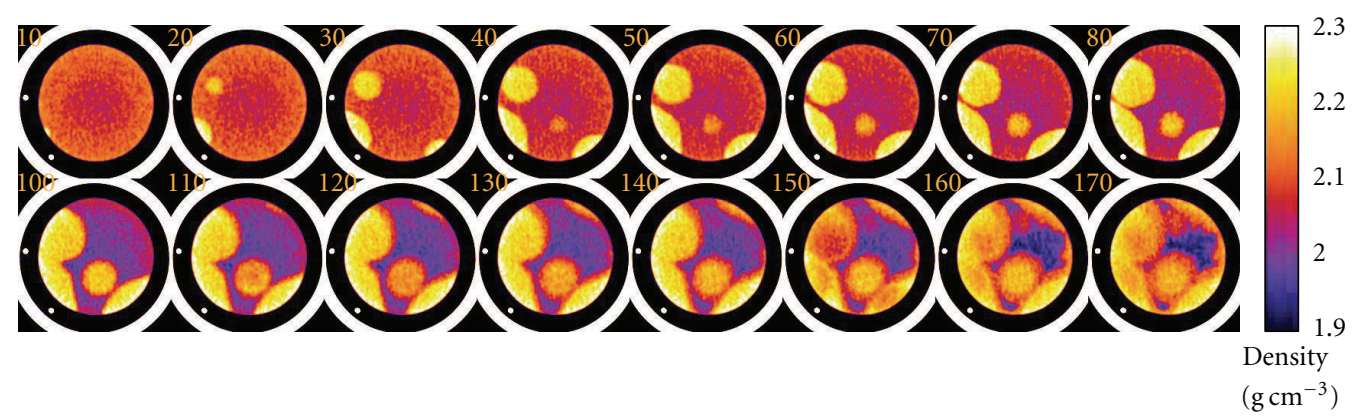

(a)

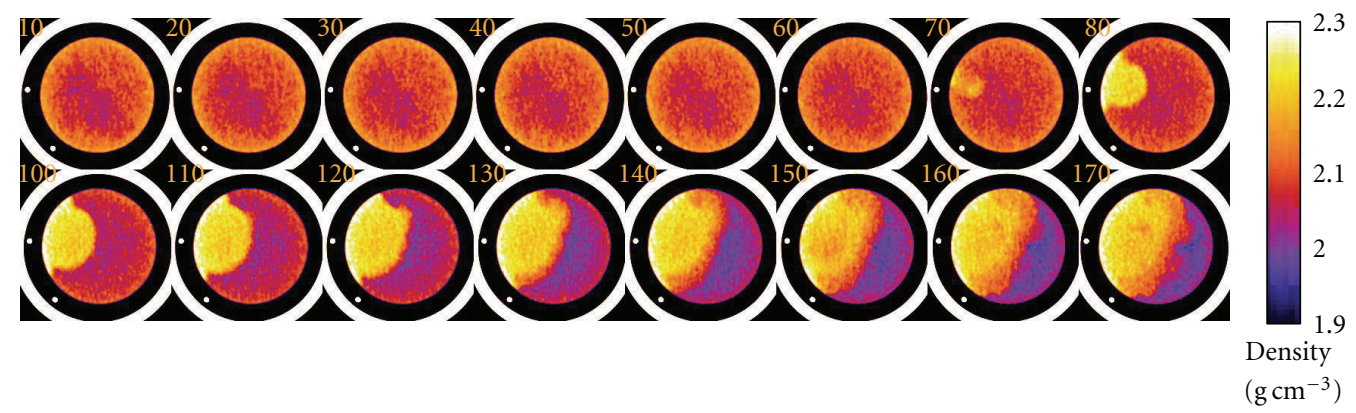

(b)

Figure 4: Methane hydrate formation at location $111 \mathrm{~mm}$ in the Mount Elbert core. (a) Test ME1.1-pressurization. (b) Test ME1.2cooling. Slices in both figures were taken at 10-minute intervals after the initial onset of hydrate formation was observed in the pressure/temperature data for each test.

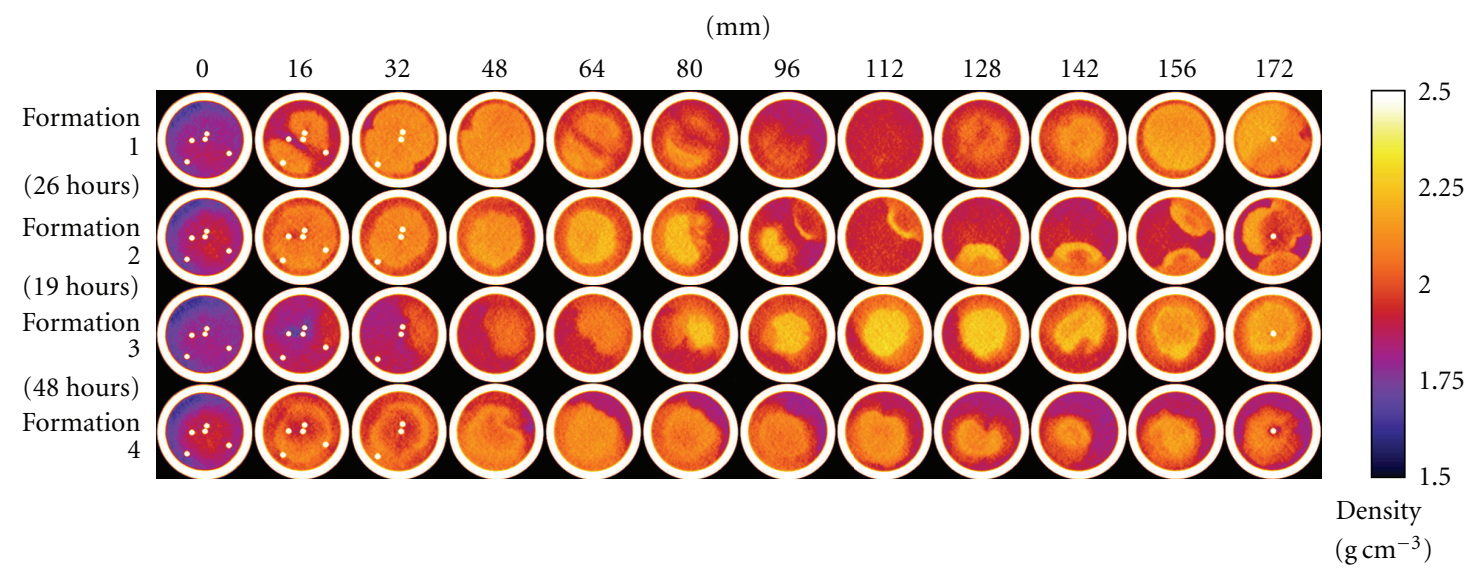

FIGURE 5: Hydrate formation distribution patterns on four consecutive formation events in packed sand sample SP1 at $8.3 \mathrm{MPa}$ and $8^{\circ} \mathrm{C}$. The time periods between dissociation and consecutive formation were varied: 26 hrs between 1 and 2; 19 hrs between 2 and 3 ; 48 hrs between 3 and 4 .

period between hydrate dissociation and reformation in the same core. Figure 5 shows the four hydrate distribution patterns in SP1, imaged following completion of hydrate formation. This figure shows that the hydrate distributions among consecutive formation events do not show a repetitive hydrate formation pattern.

Two additional hydrate formation events were conducted in SP2. Figure 6 shows the two hydrate formation events. As with the tests on the Mount Elbert core, observation time began when the pressure and temperature conditions inside the pack pass into the phase equilibrium boundary for methane hydrate. The first hydrate formation (Figure 6(a)) shows hydrate forming quickly in highly concentrated localities, but then growing outward over time. In Figure 6(b), hydrate formation occurs immediately through the entire core, but without further redistribution over the time observed (about 24 hours). In Figure 6(a), hydrate formation began at a number of locations near the gas injection point ( 32 and $50 \mathrm{~mm}$ ) as seen in the 44 minutes column. At 99 minutes, hydrate forms throughout 


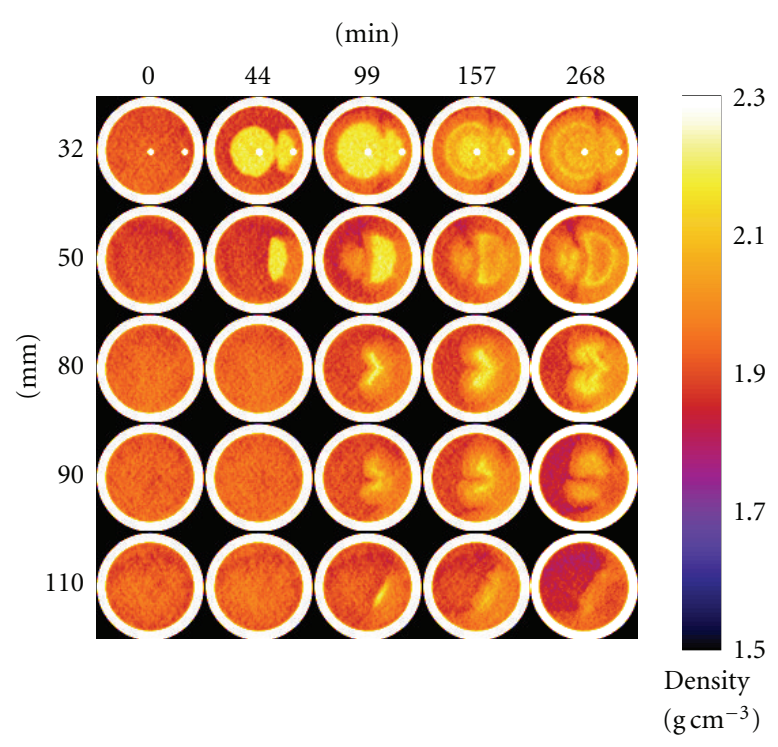

(a)

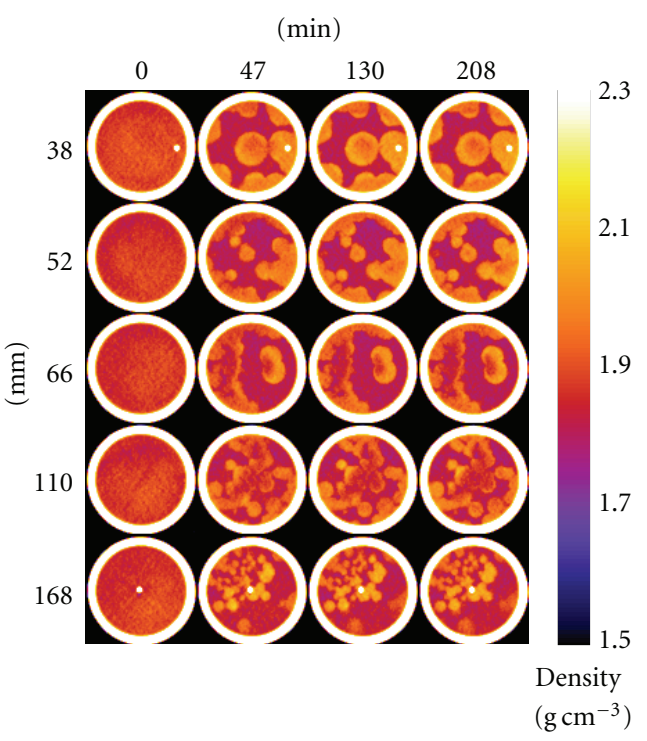

(b)

FIgURE 6: Methane hydrate formation in sample SP2. (a) First hydrate formation in SP2. (b) Second hydrate formation in SP2 after previous hydrate dissociation from (a).

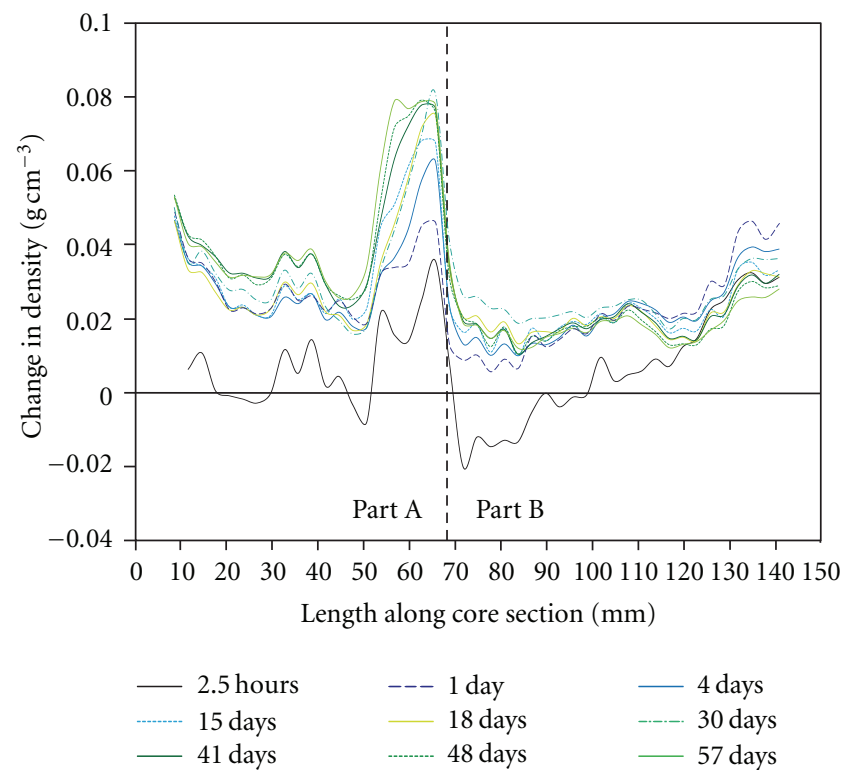

Figure 7: Profile of the average change in density of each slice at various times, from slices 5 to 48 .

the sample while further hydrate accumulation occurs at the 32 and $50 \mathrm{~mm}$ locations. During the test, as shown in Figure 6(a), the initial hydrate formation occurs soon after the application of pressure to the sand pack, indicated by the rise in temperature inside the sample and the continuous drop in pressure. At $\sim 140$ minutes, the temperature inside the sand pack increased by $0.5^{\circ} \mathrm{C}$, suggesting further hydrate formation in the sample.

Figure 6(b) shows a contrasting hydrate distribution pattern to that in Figure 6(a). Hydrate formation appears to start in many locations throughout the entire core, forming numerous separated spherical masses. Unlike the hydrate in Figure 6(a), no redistribution is detected after the initial formation pattern (47 minutes in Figure 6(b)). The pressure and temperature data also suggest that no further hydrate formation occurred after 47 minutes since no fluctuations were observed.

3.2. Long-Term Test Results. The first phase of this test sequence (Test ME2.1) showed hydrate formation initiating after only 9 minutes in the stability zone. A scan was taken 2.5 hours after the onset of hydrate formation and showed hydrate forming in localized regions throughout the core. Another scan performed after 24 hours in the stability zone, showed that hydrate formation had evened out across the core. These first scans showed that, when hydrate formed at specific locations, other areas were depleted of water, lowering the density locally in those areas. After 24 hours, hydrate formation had spread throughout the core. Figure 7 shows the density change throughout 57 days of the $\sim 60$ day time span of the test, by plotting the average density of each $x-y$ cross-section along the core length with the density obtained from the prehydrate scan subtracted. The plot for 2.5 hours shows an increase in density in the center of the core, in Part A, and an adjacent decrease in Part B, suggesting early hydrate formation depleting Part B of water. Between 2.5 hours and 1 day, hydrate continues to form and moisture redistributes itself resulting in density increase in both parts of the core, but the density in Part A close to the boundary with Part B remains higher. From 1 day to 57 days, density increases at this boundary $(50 \mathrm{~mm}$ to $70 \mathrm{~mm}$ in Figure 7), even though density change is minimal in the locations adjacent to this region. Note also that a decrease 


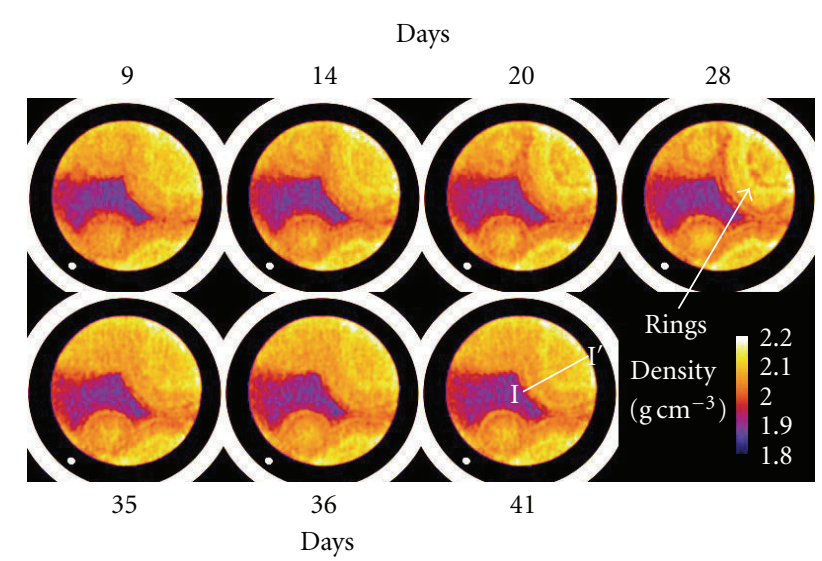

(a)

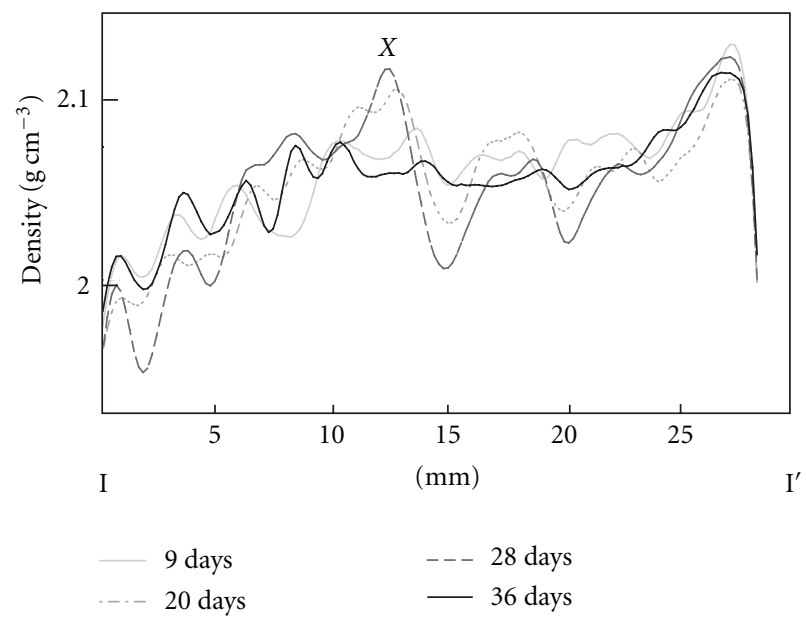

(b)

Figure 8: (a) $X-Y$ cross-sections at location $63 \mathrm{~mm}$ in the Mount Elbert core showing the development of "rings" inside a hydrate mass. (b) Density profile along the line I-I' in (a) for 4 times during Test ME2.2. $X$-axis represents millimeters along line I-I'.

in density occurs in Part B of the core between $130 \mathrm{~mm}$ and $140 \mathrm{~mm}$. It is likely that moisture from this part of the core is redistributing over this period to the center of the core.

Over the course of Test ME2.1, temperature fluctuations $\sim 0.5^{\circ} \mathrm{C}$ consistently occurred due to the daily ambient temperature changes in the laboratory. These fluctuations were well within the hydrate stability zone and were not accompanied by unexpected increases or decreases in pressure, which would indicate hydrate dissociation or formation, respectively. To investigate this further, the temperature in the control bath was dropped by $0.9^{\circ} \mathrm{C}$, corresponding to a drop in pore pressure of $0.07 \mathrm{MPa}$ on day 33 of the test sequence. The temperature was maintained at this lower value for the remainder of the test, placing the hydrate under more stable conditions. The scans from before and after this change (days 30 and 41 in Figure 7) show the higher density region between 60 and $70 \mathrm{~mm}$ in the 30 day scan thickens so that a band of higher density can be seen from 50 to $70 \mathrm{~mm}$ in the 41-day scan. This change is not greatly different from the progressive redistribution seen throughout the test and so may not be caused by the applied temperature drop.

The first CT scan in Test ME2.2 was taken $\sim 9$ days after the core returned to hydrate-stable conditions. After 9 days, methane hydrate was clearly present in distinct patches across the core. In this test, hydrate appeared to form in a more heterogeneous manner in Part A of the core than in Part B, as well as forming concentrated hydrate masses, in contrast to the relatively dispersed nature in Test ME2.1. Over the 41 day duration of Test ME2.2, systematic CT scans were taken to monitor any changes in distribution. Over the first 28 days, several hydrate masses appeared to increase in density into distinct "ring" structures (Figure 8(a)). Between the scans at 28 days and 35 days the sharp density variations disappear, with the rings becoming less evident. Figure 8 (b) highlights this change by showing a plot of density change across one of the patches. From 9 to 28 days density differences become more pronounced with a peak and trough evident between 10 and $16 \mathrm{~mm}$. The final trace at 36 days, shows the peak and trough to have disappeared, and the average density across the length of the plot to have increased slightly. At 33 days, an increase in temperature and decrease in pressure, consistent with hydrate formation, were detected inside the core. Pore pressure inside the sample (and attached bottle) dropped by $0.07 \mathrm{MPa}$, and the internal temperature of the core increased by $0.9^{\circ} \mathrm{C}$ before returning to ambient temperatures after 3 hours. The changes seen in the pressure-temperature conditions suggest further hydrate formation during the redistribution evident in the CT scans. After the scan at 36 days, the ring structures again began to become more distinct. The test sequence was ended after 42 days.

\section{Discussion}

4.1. Repeated Hydrate Formation. The first phase of testing was conducted to investigate repeated hydrate formation in a natural core sample and in a sand pack. Figure 4 compares the hydrate formation at a single location in Mount Elbert Tests ME1.1 and ME1.2. The hydrate does not display the same formation morphology between the two tests. Hydrate formed in numerous discrete, highly localized masses in Test ME1.1, while it formed in much larger clusters in Test ME1.2. These results compare favorably with the results from the packed sand sample (Figures 5 and 6), where repeated hydrate formation also yielded poor repeatability in hydrate morphology. The results from both the Mount Elbert tests and the packed sand tests would suggest that the mechanisms for repeated hydrate formation in sediments are complex and may include a number of factors.

One factor possibly controlling the varying hydrate morphology in the repeated tests could be the water distribution following hydrate dissociation. To examine this effect, water saturation in the cores was analyzed before and after hydrate formation. In both the natural sediment core and the handpacked sample, water was more concentrated in certain areas after hydrate dissociation. When this water saturation variation was compared to subsequent hydrate formation in each 


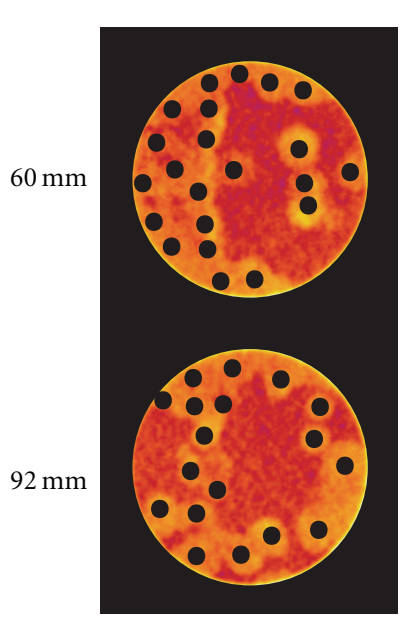

(a)

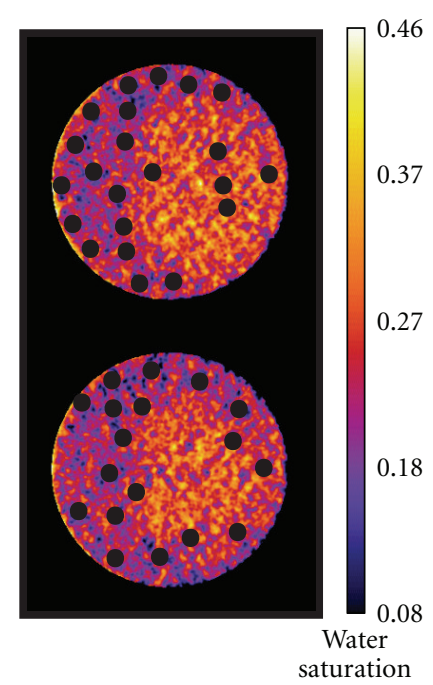

(b)

FIGURE 9: A comparison of hydrate nucleation locations with water saturation; (a) hydrate saturation distribution after the second hydrate formation in SP2 with black dots for the center of high hydrate saturation area indicating hydrate nucleation locations and (b) water distribution before the second hydrate formation with the black dots of hydrate nucleation superimposed.

sample, no correlation was observed in the Mount Elbert core from the end of test ME1.1 to the hydrate formation in ME1.2. However, the comparison in SP2 showed that hydrate formed more predominantly in areas where there was lower water saturation following hydrate dissociation. Figure 9 highlights this correlation by showing slices from two parts of the sample before and after hydrate formation. Figure 9(a) shows the sample with hydrate already formed (second formation in SP2), with black dots indicating locations of higher hydrate saturation in the sample. Figure 9(b) shows the same location for the sample prior to hydrate formation (after first hydrate dissociation in SP2), with the same black dots for hydrate formation superimposed. It can be seen from this figure that hydrate preferentially occurred in areas of lower water saturation $(<\sim 20 \%)$ in this case.

Hydrate nucleation is thought to be a process with a significant random component $[1,32]$, with the probability for nucleation increasing as the driving force of the reaction is higher, that is, the further into the hydrate stability zone the sample is placed prior to formation. All the tests described here have a relatively low driving force, defined as where the sample temperature and pressure conditions are approximately $1 \mathrm{MPa}$ above the three-phase equilibrium for methane hydrate [22]. At this low driving force, the probability of hydrate nucleation has a substantial random element. Factors such as salinity, grain size distribution, and grain composition will alter the likelihood of nucleation in one region or another [1]. Sample SP2 was formed from uniform sand with distilled water in the pore space. The hydrate formation would therefore not be affected by salinity or grain size disparities across the sample. The differences in water saturation compounded by the random nucleation are therefore likely to be the main controlling factors in distribution within sample SP2. Figure 9 shows hydrate preferentially growing in areas of lower initial water saturation, adjacent to areas where the water saturation is higher. This would suggest that small accumulations of water at grain contacts promote hydrate formation over large accumulations, which could be due to the influence of the surface of the sand grains on the structure of the water.

When water is in contact with a hydrophilic surface such as silica, water molecules will orientate in response to the charge on the surface of the mineral [33]. This "ordering" of the water molecules, called a hydration shell, is transmitted into the bulk of the water, becoming less ordered with increasing distance away from the mineral surface [34]. Hydration shells may provide an order to the water molecules that increases the probability of hydrate nucleation in porous media when water saturation is low. Although the hydration shells around the sand grains in SP2 would be considered relatively large at the nanometer scale, the variation in grain roughness might provide thinner films at the "peaks" of protrusions on rough grains, which could supply ordered nucleation sites for hydrate. Once water saturations become higher, the distance from the mineral surface to the gas/water interface is increased, and the effect of ordering from the hydration shells may not contribute as much to nucleation probability. Stevens et al. [35] and Bagherzadeh et al. [36] also observed that hydrate formation in low water saturation sandstone cores was faster than in high water saturation samples.

Although the hand-packed sand samples appear to show a correlation between water saturation and the location of reformed hydrate, the natural sediment samples did not show the same relationship. Distribution of water before and after each hydrate formation event was analyzed, with no correspondence seen throughout the core. Other factors affecting the nucleation probability in the Mount Elbert core 
must therefore be considered, such as salinity variations, grain distribution, and thermal history.

The original salinity of the pore water in the Mount Elbert core was $\sim 4$ ppt [37]. Nevertheless, the inclusion of salts into water alters the stability conditions of methane hydrate, requiring higher pressures and lower temperatures for stability and making it slightly harder for hydrate to nucleate in certain regions. Variable salinity across the core, caused by dissociation of hydrate yielding fresh water in certain areas, but leaving others with a higher salinity, may have predestined some areas of the core to subsequent hydrate formation. This would imply that hydrate would tend to reform in the same locations it previously occupied. Once again, however, analysis of the scans does not suggest any control from potential salinity variations.

It is also possible that thermal history may play a role in influencing the nucleation of hydrate across a sediment core, in addition to salinity variability and saturation variations. Tests ME1.1 and ME1.2 do not share the same thermal history with regard to applied conditions for methane hydrate stability. Test ME1.1 began by cooling the sediment to $4^{\circ} \mathrm{C}$ at a pressure outside the stability zone and once temperature had stabilized, increasing the pressure to within the stability zone (4.4 MPa). Alternatively, Test ME1.2 started with the core at $4.4 \mathrm{MPa}$ pressure but at $10^{\circ} \mathrm{C}$, before instigating hydrate formation by cooling the core to $4^{\circ} \mathrm{C}$. The induction times for these two tests may indicate the difference in thermal history experienced in the core. Hydrate began forming 13 minutes after application of stability conditions in Test ME1.1 but took 80 minutes to begin forming in Test ME1.2. In addition, in Test ME1.2, the outer regions of the core would have been in the hydrate stability zone longer than the inner regions because of heat transfer.

When considering whether the thermal gradient inside the core could be a factor, examination of the temperature data from the outside and inside the core shows that it takes $\sim 14$ minutes for temperatures on the outside of the core to be transmitted to the center. Temperature data from Test ME1.2 also shows that internal temperatures had equilibrated with the outer edge of the core prior to hydrate formation, so it would seem that temperature gradients do not directly affect formation of hydrate here. However, they may contribute to the water distribution. Analysis of the CT scans gives no indication of thermal history control on distribution, with hydrate forming both at the edges and inside of the core in equal measure.

One observation that can be made from the repeated tests on the Mount Elbert core is the significance of the random aspect of hydrate nucleation. Sloan and Koh [1], Parent and Bishnoi [32], and Servio and Englezos [22] all stress that, at low driving forces, hydrate nucleation is a random process influenced by grain characteristics, salinity, and thermal history of the pore water [1]. It can be determined from these tests that, in a system with no salinity and a consistent thermal history, water saturation has the most influence on hydrate nucleation probability. However, in a natural system where there are several aspects in conflict, no one factor seems to control hydrate nucleation, and the probabilities are not altered to favor specific locations.
4.2. Memory Effect. The memory effect can have a strong influence on the induction time of hydrate nucleation [1723]. The memory effect was observed to influence hydrate formation in the hand-packed sand samples SP1 and SP2, as subsequent hydrate formation occurred almost instantaneously after hydrate had been formed and decomposed inside the sand once. In the Mount Elbert core, the memory effect did not appear to occur between ME1.1 and ME1.2 (recall test ME1.2 formed hydrate by cooling, and the sample remained at $10^{\circ} \mathrm{C}$ for 24 hours prior to hydrate formation) since the induction time increased between the two tests instead of decreasing. The changing induction times seen in tests ME1.1 and ME1.2 may result from the varying thermal history between the cores. Test ME1.1 on the Mount Elbert core sample formed hydrate through pressurization, but the core was maintained at $4^{\circ} \mathrm{C}$ for at least 12 hours prior to hydrate formation. These differences in thermal history could be responsible for the differences in induction time seen between the tests, as Ohmura et al. [19] have shown that induction times for methane hydrate formation increase as the temperature at which the system was held after dissociation increases.

The memory effect has been linked to the timing of hydrate formation, but not to its location. The memory effect does not affect the location of hydrate formation in repeated tests. Water distribution is shown to have the most control over hydrate location in the packed sand samples. In the Mount Elbert core, no correlation can be seen between old and new hydrate formation in the cores, indicating that prior hydrate formation has no effect on location of hydrate nucleation.

4.3. Density Redistribution. Because the sand in our samples was held in place by a combination of cementation and effective stress, density changes were caused by (1) incorporation of methane into water, resulting in hydrate increasing the mass in a voxel of fixed volume or (2) the change in location of water or hydrate within the pore space. Density redistribution was seen to occur over two timescales: (1) short term, over the hours it takes for hydrate to fully form (Tests ME1.1, 1.2, 2.1, and SP2), and (2) long term, over, several weeks (Tests ME2.1 and ME2.2).

4.3.1. Short-Term Density Redistribution. In Test ME2.1 (pressurization), hydrate formation during the initial 2.5 hours produced patchy and localized regions of elevated hydrate saturation in the sediment, which became more homogeneous over 24 hours and with full hydrate formation. Early and more localized density redistribution was also seen in the hydrate formed in Tests ME1.1 and ME1.2 and in the packed sand sample SP2. Two processes need to be considered with regard to the density redistribution observed across these tests: capillarity and recrystallization.

Capillarity will cause water to be drawn towards the hydrate formation front. The physical presence of waterwetting hydrate in the pore space (1) reduces pore sizes, thus strengthening capillary suction, and (2) changes surface energy, increasing the capillary suction locally [38-40]. This 

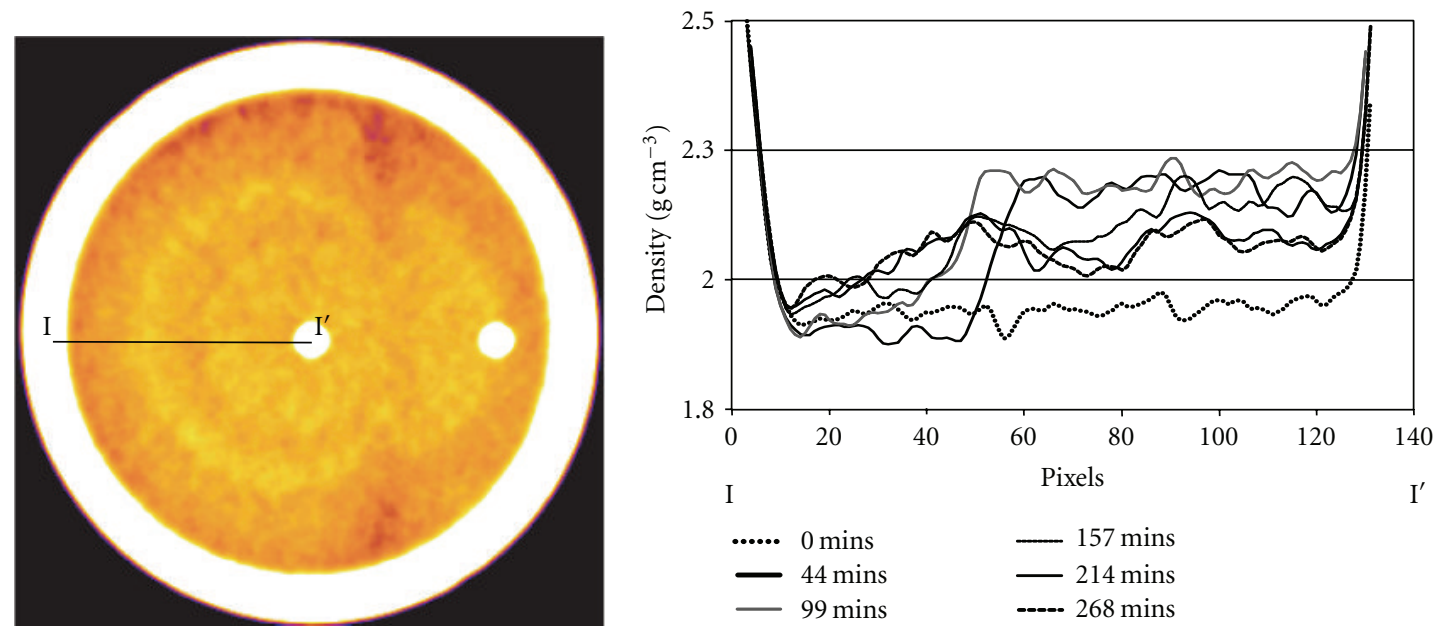

Figure 10: Cross-sectional profiles of density in the core (I to I' at $32 \mathrm{~mm}$ from the injection point) showing the evolution of density distribution patterns.

change in capillary pressure results in water being drawn towards the forming hydrate and therefore in an increase in local density due to water accumulation (in addition to hydrate formation) seen in the CT scans. This also creates areas of lower density nearby where water is depleted, such as in the plot for 2.5 hours over the region 70 to $90 \mathrm{~mm}$ in Figure 7 from Test ME2.1. Rapid placement of samples into the hydrate stability zone caused fast nucleation (as described in earlier sections). Visual inspection of fast hydrate growth $[14,15,22]$ has shown that hydrate forms in dendritic crystals with high surface areas. Over time, these dendritic crystals recrystaleize into more energy-efficient configurations $[14,15,22]$. The presence of these more compact, energy-efficient configurations in the porous medium results in a lower capillary suction than when the dendritic hydrate previously occupied the pore space.

Figure 10 shows the change in density during the first hydrate formation in SP2 over time for a single slice of the sample. Initial hydrate formation caused a high-density region (highly hydrate- and water-saturated) in the center of the sample (see also Figure 6). The initial rapid nucleation of hydrate in the sample would have likely created dendritic hydrate crystals with high surface areas and unstable surface energies. As time progresses ( $t>157$ minutes), the density in the center decreases, while the density outside the center increases and an outer circular band forms. This change in distribution is consistent with the dendritic hydrate crystals reconfiguring into more energy-efficient shapes [40] and the resulting water movement. The dendritic hydrate holds the water that was initially present and draws water towards itself due to capillarity. As the hydrate recrystaleizes into more compact forms, the heightened capillary suction around the reformed crystals is reduced and water redistributes away from the early hydrate growth area. The same effect is seen in the hydrate growth patterns in Figure 4. As hydrate reconfigures and continues to form across the core, a density increase can be seen everywhere (plot for 1 day in Figure 7).
The observations of Servio and Englezos [22] regarding hydrate crystal reconfiguration may help explain why this dispersive nature is not seen in the second hydrate formation in SP2. In Figure 6b, hydrate forms in concentrated masses that do not disperse as formation matures. Servio and Englezos [22] show that, when repeating hydrate formation in droplets of water, dendritic crystals do not form during the second hydrate nucleation phase if the time between decomposition and reformation is short $(<24 \mathrm{hrs})$. It is possible that the time period between hydrate formations in SP2 was short enough in this case $(<16 \mathrm{hrs})$ to allow the water to retain a memory of the hydrate formation.

4.3.2. Long-Term Density Redistribution. The long-term tests conducted with the Mount Elbert Core sample, ME2.1 and ME2.2, show density redistribution over several weeks. In Test ME2.1, density was redistributed over the scale of several centimeters, with a large increase in density occurring near the interface between the two regions in the sample, primarily on the higher porosity and larger grain size side. This redistribution is particularly apparent with the changing peak in density between $50 \mathrm{~mm}$ and $70 \mathrm{~mm}$ in Figure 7. In Test ME2.2, rings of adjacent high and low density can be seen to form in areas of hydrate formation over a period of 28 days (Figure $8(\mathrm{a})$ ). These changes can be attributed to two processes: (1) hydrate dissociation in one location and reformation in another; (2) water migration due to capillary pressure gradients caused by the hydrate formation and configuration changes.

Hydrate dissociation and reformation in equal amounts could occur if either water or gas was available in a limiting quantity. Since gas was present in excess (macroscopically), water can be considered as the limiting reagent. Under equilibrium conditions, some hydrate is dissociating while forming in equal amounts in other areas. Over long timescales, more hydrate would dissociate in less energetically favorable locations and more would form in more favorable locations 
(much like ice in a non-frost-free freezer sublimates from the ice cube tray and precipitates on the freezer wall).

The second process, water migration caused by hydrate formation and configuration changes, could also be responsible for the density changes observed. Calculations of initial water content and gas uptake during hydrate formation indicate only a $70 \%$ conversion of total water to hydrate in Tests ME2.1 and ME2.2. The remaining water could be considered to be bound to grain surfaces and unavailable for hydrate formation due to its low chemical potential $[40,41]$, or some water may be completely occluded from the methane gas by hydrate. Water bound to surfaces is still mobile and can move in response to capillary pressure changes in the sediment as long as the phases are interconnected at grain contacts [42]. Because the sample was heterogeneous on many scales, capillary pressure would result in different water saturations throughout the core under prehydrate equilibrium conditions. Hydrate formation changed these equilibrium conditions and resulted in water migration. Because of the randomness of the resulting hydrate configuration, the hydrate is not likely to be in its lowest energy equilibrium configuration and will continue to reduce its surface area to minimize energy. These changes in the hydrate configuration impact the capillary suction of the sediment, resulting in further water migration.

Over the first 57 days in Test ME2.1 and 9-28 days in Test ME2.2, the pressure and temperature measurements inside the sample showed no anomalous decreases or spikes, respectively, indicating that neither of the processes described above caused additional hydrate formation in the core. Note that slight thermal gradients occurred in the sample from daily temperature changes in the laboratory impacting the temperature-controlled bath, tubing, and jacket. In addition, slight pressure fluctuations occurred from room temperature changes affecting the external gas bottle, causing the pressure to increase when the room temperature increased. In spite of these oscillations in pressure and temperature, the sample was maintained well within the stability zone for the test duration.

Density redistribution from the above processes can be seen in Test ME2.1 (Figure 7). The peak in hydrate content localized between 50 and $70 \mathrm{~mm}$ after 1 day in Test ME2.1 (Figure 7) would have caused a capillary pressure gradient to have developed between Parts A and B. Water slowly moved toward that location in response to this gradient resulting in density increases in the region between 50 and $70 \mathrm{~mm}$. The overall density in Part A increased whereas the overall density of Part B decreased. Part A therefore had a larger hydrate content than Part B following initial hydrate formation (1 day in Figure 7). This higher hydrate content caused Part A to have a larger capillary suction than that of Part B after 1 day, and water was drawn to Part A over the next 57 days as a result.

Density changes seen in the first 28 days of Test ME2.2 could also be caused by the movement of free water due to capillary pressure gradients. A number of hydrate patches formed predominantly in Part A of the core during Test ME2.2. Within these masses, slight variations in hydrate content would draw water towards certain areas, increasing

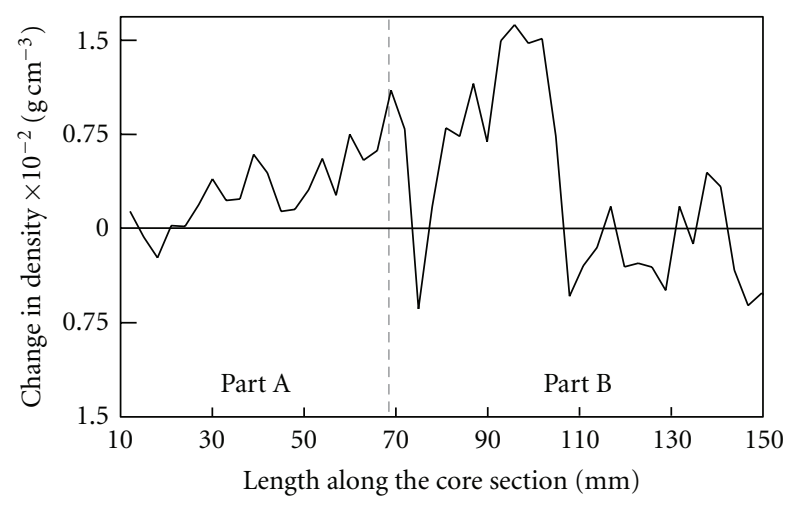

FIGURE 11: Density change along the length of the core between day 28 and day 35 in Test ME2.2. New hydrate formation was indicated by a temperature spike on day 33 of the test.

the density locally. In adjacent areas, the density would decrease where water was depleted. These regions can be seen as ring structures in Figure 8(a).

4.3.3. Additional Hydrate Formation in ME2.2. A hydrate formation event occurred on the 33rd day of Test ME2.2, resulting in a drop in pressure $(0.07 \mathrm{MPa})$ and spike in temperature $\left(0.9^{\circ} \mathrm{C}\right)$. The temperature spike was observed in Part A of the core 10 minutes before the Part B side, indicating that the location of hydrate formation was closer to the A side thermocouple. CT scans show that density increased in both parts, with the largest increase occurring between 80 and $110 \mathrm{~mm}$ (Part B, see Figure 11). The CT data also shows the disappearance of the rings of density variation (Figure $8(\mathrm{~b})$ ). The density equilibration over the region between 10 and $16 \mathrm{~mm}$ along line ${\mathrm{I}-\mathrm{I}^{\prime}}^{\text {indicates }}$ that the redistribution in this region was most likely from moisture movement. If hydrate had reconfigured in this ring, the density would not have decreased (for a hydrate formation event) at Point $X$ in Figure 8(b).

The most likely explanation for additional hydrate forming in Test ME2.2 after 33 days in the stability zone is that water that had been isolated from the methane gas in the pore space during initial hydrate formation became exposed. Instances of exposure of isolated water have been indicated in previous hydrate formation tests $[39,43]$, where initial hydrate formation isolates gas and water from each other, ceasing hydrate formation until there is a "punchthrough" and water and methane components come into contact once more. Kneafsey et al. [39] observed punchthrough over 24 hours during the early stages of hydrate formation, and Linga et al. [43] saw several temperature spikes over a period of 75 hours during hydrate formation in a sand pack, indicating a new hydrate formation event. This punch-through phenomena has not been observed over longer time periods.

A punch-through occurrence during Test ME2.2 would be a localized event. However, the disappearance of the ring structures and redistribution of density across the core occur sample wide. There are a number of possibilities for this 
global redistribution of density. We assume that the change in density seen in Figure 11 is due to water movement, in addition to new hydrate formation. With this in mind, three hypotheses can be made with regard to the cause of the water movement during this time: (1) expansion of trapped gas due to pressure decrease, (2) gas coming out of solution due to temperature changes during hydrate formation, and (3) local redistribution of moisture due to capillary pressure changes because of the presence of new hydrate formation.

First, water could have been redistributed by the expansion of trapped gas inside hydrate masses. This would account for a reduction in density in the rings (as seen in Figure 8) in addition to the increase in density caused by hydrate formation. This hypothesis assumes, however, that there was trapped gas in each of the ring regions.

The second hypothesis accounts for the global change in density observed across the core by considering the change in temperature that resulted from the new hydrate formation. If liquid water was accumulating in regions of higher hydrate saturation due to capillary pressure gradients, the rings would have higher unconverted water saturations than the adjacent areas. The $0.9^{\circ} \mathrm{C}$ increase in temperature caused by hydrate formation (temperature in the sample was $0.9^{\circ} \mathrm{C}$ above bath temperature for 60 minutes) may have caused more methane to dissolve into solution in the residual water in the rings, as methane solubility increases with temperature when in the presence of hydrate [44-46]. Once hydrate formation was over and the temperature returned to the previous conditions ( 3 hours after initial temperature increase), the dissolved methane exsolved from solution forming bubbles and pushing water out of the higher density regions, causing a drop in density in those regions. This density change is consistent with the disappearance of the peak at Point $X$ in Figure 8(b). Formation of bubbles in such small pore spaces under these conditions may not be possible however.

The third hypothesis assumes that the new hydrate formation that occurred on day 33 of the test altered the capillary pressures in the core and caused moisture redistribution as a result. New hydrate formation in certain pores would increase capillary suction by reducing pore size locally. The increased capillary suction in these areas would draw residual water away from previous accumulations (rings) and redistribute density in the core. Interpretation of the results discussed in previous sections agrees with this hypothesis; however it would occur locally to where hydrate formed, and density redistribution was seen globally in each ring structure not just in isolated regions.

It is possible that a combination of processes is responsible for the density changes seen throughout the core between days 28 and 35 of test ME2.2. The global nature of the redistribution indicates that a response to the temperature and/or pressure changes during new hydrate formation may be responsible; however, the results from tests ME1.1, 1.2, and 2.1 suggest that the capillary pressure alterations caused by additional hydrate presence should not be discounted.

Between 35 and 41 days in Test ME2.2, the ring structures began to appear once again in the hydrate masses. The higher local capillary suction that caused the rings to occur between days 9 and 28 would not have changed significantly during the hydrate formation event at 33 days. Even if new hydrate formed elsewhere, the larger accumulations of hydrate in the masses in Part A would still impart capillary pressure gradients that would draw the water into ring-like structures again. In addition, more hydrate could form around the new gas bubbles, increasing capillary suction further and drawing water into those regions once again.

This study has a number of implications regarding forming hydrate in the laboratory, as well as our understanding of natural hydrate deposits. Previous assumptions that methane hydrate is an immobile mass in porous media must be reconsidered. Short-term redistribution of methane hydrate as it grows in a sediment must be accounted for by those making physical measurements because the changing morphology will impact physical characteristics until complete hydrate formation has been achieved. In addition, long-term observation of hydrate-bearing sediments has shown that the capillary suction differences imposed in a sediment due to hydrate formation can cause moisture and/or hydrate to redistribute weeks after initial hydrate formation has been completed.

\section{Conclusions}

Methane hydrate was repeatedly formed and dissociated in a natural sediment core from the Mount Elbert Stratigraphic Test Well, as well as in laboratory sand packs, to investigate hydrate redistribution in sediments over time and the growth patterns of hydrate when made repeatedly in the same material. CT scanning was employed in both sets of experiments to directly observe hydrate structure within the cores.

Results from repeated hydrate formation experiments showed that hydrate formed randomly across the cores indicating that numerous factors affect hydrate formation. Hydrate nucleation is a random process, with salinity, saturation of the pore water, grain size distribution, and mineralogy each altering the probability of nucleation under the low driving force formation conditions. In the samples with no pore water salinity and uniform grain-size, water saturation variation was the dominant control on the location of reformed hydrate, with hydrate forming preferentially in areas of lower water saturation adjacent to regions of higher water saturation. In the natural sample with varying pore water salinity and grain size distribution, no correlation between previous hydrate formation and water saturation, salinity or mineralogy changes could be found to affect the location of hydrate formation in the core. The random nature of hydrate formation dominates nucleation location in this case. The memory effect did not control the location of nucleation events in reforming hydrate in these samples in spite of reducing the time needed for hydrate to begin forming.

Density redistribution was observed in both short- and long-term tests. Over the time period of hydrate formation (hours), density variations occurred whereby hydrate masses went from being concentrated to disperse. This change is 
attributed to early rapid hydrate formation in dendritic, high surface energy morphologies, then recrystallizing as hydrate formation progressed into more energy-efficient crystal configurations. Over the long-term tests, density redistributions were observed over periods of up to 60 days, which we attribute to mobile free water in the samples being drawn to areas of high capillary suction causing areas of higher density. We believe this moisture redistribution also caused renewed hydrate formation in one test by exposing previously trapped water so that it became available for more hydrate formation.

The results from the tests described in this paper suggest that in natural hydrate-bearing deposits, hydrate and residual moisture may not be stagnant phases and are likely to redistribute in response to stimuli. These stimuli include the thermal gradient changes that could occur from wells or pipelines carrying fluid at a different temperature than that of the ambient conditions.

\section{Acknowledgments}

This work was supported by the Assistant Secretary for Fossil Energy, Office of Oil and Natural Gas, Gas Hydrate Program, through the National Energy Technology Laboratory of the US Department of Energy under Contract no. DE-AC0205CH11231. The authors would also like to thank Kelly Rose and Kyle Littlefield of NETL for providing the grain size distributions and mineralogy of the Mount Elbert core sample.

\section{References}

[1] E. D. Sloan and C. A. Koh, Clathrate Hydrates of Natural Gases, CRC Press, New York, NY, USA, 3rd edition, 2008.

[2] W. F. Waite, J. C. Santamarina, D. D. Cortes et al., "Physical properties of hydrate-bearing sediments," Reviews of Geophysics, vol. 74, no. 4, p. RG4003, 2009.

[3] K. Kvenvolden and T. McDonald, "Gas hydrates of the Middle America Trench, deep sea drilling project Leg 84," in Initial Reports of the Deep Sea Drilling Project, R. Von-Huene and J. Aubouin, Eds., pp. 664-682, U.S. Government Printing Office, Washington, DC, USA, 1985.

[4] P. G. Brewer, F. M. Orr, G. Friederich et al., "Deep-ocean field test of methane hydrate formation from a remotely operated vehicle," Geology, vol. 25, no. 5, pp. 407-410, 1997.

[5] T. Collett, M. Riedel, and J. Cochran, "Indian national gas hydrate program expedition 01 initial reports," Tech. Rep., Indian Directorate General of Hydrocarbons, 2008.

[6] A. M. Trehu, F. R. Rack, and M. Chapman, "Drilling gas hydrates on hydrate ridge, cascadia continental margin," in Proceedings of the Ocean Drilling Program Scientific Results Leg 204, Ocean Drilling Program, College Station, Tex, USA, 2006.

[7] G. K. Westbrook et al., "Proceedings ocean drilling program, initial reports," Ocean Drilling Program, 146, 1994.

[8] L. M. Kraemer, R. M. Owen, and G. R. Dickens, "Lithology of the upper gas hydrate zone, blake outer ridge: a link between diatoms, porosity and gas hydrate," in Proceedings of the Ocean Drilling Program Results, C. Paull, R. Matsumoto, and P. Wallace, Eds., pp. 229-236, Ocean Drilling Program, 2000.

[9] M. Riedel, T. S. Collett, M. J. Malone, and The Expedition 311 Scientists, "Cascadia margin gas hydrates," in Proceedings of the Integrated Ocean Drilling Program Expedition Reports, Integrated Ocean Drilling Program Management International, 2006.

[10] S. R. Dallimore, T. Uchida, and T. Collett, "Results from Japex/Jnoc/Gsc mallik 2l-38 gas hydrate research well, mackenzie delta, northwest Territories, Canada," Geological Survey of Canada Bulletin, no. 544, 1999.

[11] W. F. Waite, W. J. Winters, and D. H. Mason, "Methane hydrate formation in partially water-saturated Ottawa sand," American Mineralogist, vol. 89, no. 8-9, pp. 1202-1207, 2004.

[12] W. J. Winters, I. A. Pecher, W. F. Waite, and D. H. Mason, "Physical properties and rock physics models of sediment containing natural and laboratory-formed methane gas hydrate," American Mineralogist, vol. 89, no. 8-9, pp. 1221-1227, 2004.

[13] M. Holland, P. Schultheiss, J. Roberts, and M. D. Geotek, "Observed gas hydrate morphologies in marine sediments," in Proceedings of the 6th International Conference on Gas Hydrates, Vancouver, Canada, 2008.

[14] B. Tohidi, R. Anderson, M. B. Clennell, R. W. Burgass, and A. B. Biderkab, "Visual observation of gas-hydrate formation and dissociation in synthetic porous media by means of glass micromodels," Geology, vol. 29, no. 9, pp. 867-870, 2001.

[15] D. Katsuki, R. Ohmura, T. Ebinuma, and H. Narita, "Formation, growth and ageing of clathrate hydrate crystals in a porous medium," Philosophical Magazine, vol. 86, no. 12, pp. 1753-1761, 2006.

[16] D. Katsuki, R. Ohmura, T. Ebinuma, and H. Narita, "Methane hydrate crystal growth in a porous medium filled with methane-saturated liquid water," Philosophical Magazine, vol. 87, no. 7, pp. 1057-1069, 2007.

[17] P. Buchanan, A. K. Soper, H. Thompson et al., "Search for memory effects in methane hydrate: structure of water before hydrate formation and after hydrate decomposition," The Journal of Chemical Physics, vol. 123, no. 16, p. 164507, 2005.

[18] J. D. Lee, R. Susilo, and P. Englezos, "Kinetics of structure H gas hydrate," Energy and Fuels, vol. 19, no. 3, pp. 1008-1015, 2005.

[19] R. Ohmura, M. Ogawa, K. Yasuoka, and Y. H. Mori, "Statistical study of clathrate-hydrate nucleation in a water/hydrochlorofluorocarbon system: search for the nature of the 'memory effect', Journal of Physical Chemistry B, vol. 107, no. 22, pp. 5289-5293, 2003.

[20] P. M. Rodger, "Methane hydrate: melting and memory," Annals of the New York Academy of Sciences, vol. 912, pp. 474482, 2000.

[21] J. P. Schroeter, R. Kobayashi, and M. A. Hildebrand, "Hydrate decomposition conditions in the system H2S-methanepropane," Industrial \& Engineering Chemistry Fundamentals, vol. 22, no. 4, pp. 361-364, 1983.

[22] P. Servio and P. Englezos, "Morphology of methane and carbon dioxide hydrates formed from water droplets," AIChE Journal, vol. 49, no. 1, pp. 269-276, 2003.

[23] T. Uchida, T. Ebinuma, and H. Narita, "Observations of CO2hydrate decomposition and reformation processes," Journal of Crystal Growth, vol. 217, no. 1, pp. 189-200, 2000.

[24] T. J. Kneafsey, L. Hailong, W. William et al., "Examination of core samples from the mount Elbert gas hydrate stratigraphic test well, Alaska North Slope: effects of retrieval and preservation," Marine and Petroleum Geology, vol. 28, no. 2, pp. 381393, 2011.

[25] R. Boswell, K. Rose, T. S. Collett et al., "Geologic controls on gas hydrate occurrence in the Mount Elbert prospect: 
Milne Point Unit, Alaska North Slope," Marine and Petroleum Geology, vol. 28, no. 2, pp. 589-607, 2010.

[26] T. S. Collett, M. W. Lee, W. F. Agena et al., "Permafrost associated natural gas hydrate occurrences on the Alaska North Slope," Marine and Petroleum Geology, vol. 28, no. 2, pp. 279-294, 2009.

[27] K. Rose, R. Boswell, and T. Collett, "BPXA-DOE-USGS Mount Elbert gas hydrate stratigraphic test well: coring operations, core sedimentology and lithostratigraphy," Marine and Petroleum Geology, vol. 28, no. 2, pp. 311-331, 2010.

[28] T. J. Kneafsey and G. J. Moridis, "Methane hydrate dissociation by depressurization in a mount Elbert Sandstone sample: experimental observations and numerical modeling," in Proceedings of the Arctic Technology Conference, Houston, Tex, USA, 2011.

[29] T. Uchida, S. Takeya, E. M. Chuvilin et al., "Decomposition of methane hydrates in sand, sandstone, clays and glass beads," Journal of Geophysical Research: B, vol. 109, no. 5, pp. B0520612, 2004.

[30] Y. Seol and T. J. Kneafsey, "Methane hydrate induced permeability modification for multiphase flow in unsaturated porous media," Journal of Geophysical Research, vol. 116, no. B8, Article ID B08102, 15 pages, 2011.

[31] G. C. Cho, J. Dodds, and J. C. Santamarina, "Particle shape effects on packing density, stiffness, and strength: natural and crushed sands," Journal of Geotechnical and Geoenvironmental Engineering, vol. 132, no. 5, pp. 591-602, 2006.

[32] J. S. Parent and P. R. Bishnoi, "Investigations into the nucleation behaviour of methane gas hydrates," Chemical Engineering Communications, vol. 144, pp. 51-64, 1996.

[33] J. Israelachvili, Intermolecular and Surface Forces, Academic Press, New York, NY, USA, 2nd edition, 1992.

[34] D. Grasso, K. Subramaniam, M. Butkus, K. Strevett, and J. Bergendahl, "A review of non-DLVO interactions in environmental colloidal systems," Reviews in Environmental Science and Biotechnology, vol. 1, no. 1, pp. 17-38, 2002.

[35] J. C. Stevens, B. A. Baldwin, A. Graue, G. Ersland, J. Husebo, and J. J. Howard, "Measurements of hydrate formation in sandstone," Petrophysics, vol. 49, no. 1, pp. 67-73, 2008.

[36] S. A. Bagherzadeh, I. L. Moudrakovski, J. A. Ripmeester, and P. Englezos, "Magnetic resonance imaging of gas hydrate formation in a bed of silica sand particles," Energy and Fuels, vol. 25, no. 7, pp. 3083-3092, 2011.

[37] M. E. Torres, T. Collett, K. Rose, J. C. Sample, W. Agena, and E. Rosenbaum, "Pore fluid geochemistry from the Mount Elbert gas hydrate stratigraphic test well, Alaska North Slope," Marine and Petroleum Geology, vol. 28, no. 2, pp. 332-342, 2009.

[38] A. Gupta, T. J. Kneafsey, G. J. Moridis, Y. Seol, M. B. Kowalsky, and E. D. Sloan, "Composite thermal conductivity in a large heterogeneous porous methane hydrate sample," Journal of Physical Chemistry: B, vol. 110, no. 33, pp. 16384-16392, 2006.

[39] T. J. Kneafsey, L. Tomutsa, G. J. Moridis et al., "Methane hydrate formation and dissociation in a partially saturated core-scale sand sample," Journal of Petroleum Science and Engineering, vol. 56, no. 1-3, pp. 108-126, 2007.

[40] M. B. Clennell, M. Hovland, J. S. Booth, P. Henry, and W. J. Winters, "Formation of natural gas hydrates in marine sediments 1. Conceptual model of gas hydrate growth conditioned by host sediment properties," Journal of Geophysical Research: $B$, vol. 104, no. 10, pp. 22985-23003, 1999.
[41] T. R. Carlisle and G. W. Hodgson, "The formation of naturalgas hydrates in sedimentary rock," Chemical Geology, vol. 49, no. 1-3, pp. 371-383, 1985.

[42] P. Hoekstra and R. D. Miller, "On the mobility of water molecules in the transition layer between ice and a solid surface," Journal of Colloid And Interface Science, vol. 25, no. 2, pp. 166-173, 1967.

[43] P. Linga, C. Haligva, S. C. Nam, J. A. Ripmeester, and P. Englezos, "Gas hydrate formation in a variable volume bed of silica sand particles," Energy and Fuels, vol. 23, no. 11, pp. 5496-5507, 2009.

[44] Y. P. Handa, "Effect of hydrostatic pressure and salinity on the stability of gas hydrates," Journal of Physical Chemistry, vol. 94, no. 6, pp. 2652-2657, 1990.

[45] P. Servio and P. Englezos, "Measurement of dissolved methane in water in equilibrium with its hydrate," Journal of Chemical and Engineering Data, vol. 47, no. 1, pp. 87-90, 2002.

[46] Y. S. Kim, B. D. Lim, J. E. Lee, and C. S. Lee, "Solubilities of carbon dioxide, methane, and ethane in sodium chloride solution containing gas hydrate," Journal of Chemical and Engineering Data, vol. 53, no. 6, pp. 1351-1354, 2008. 

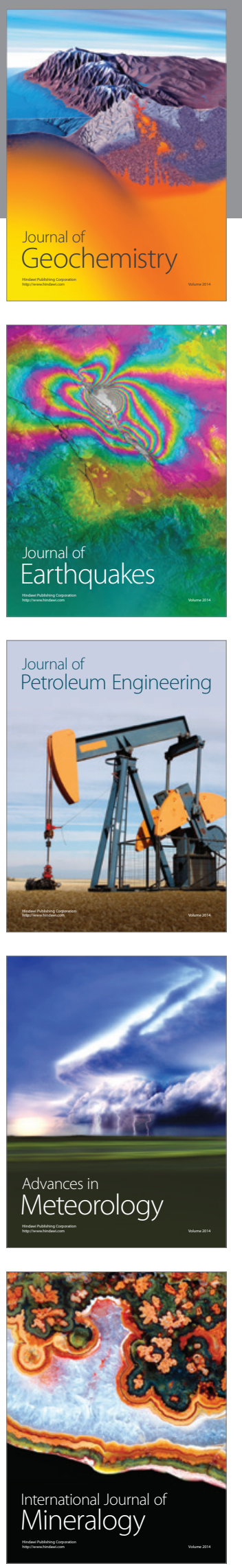
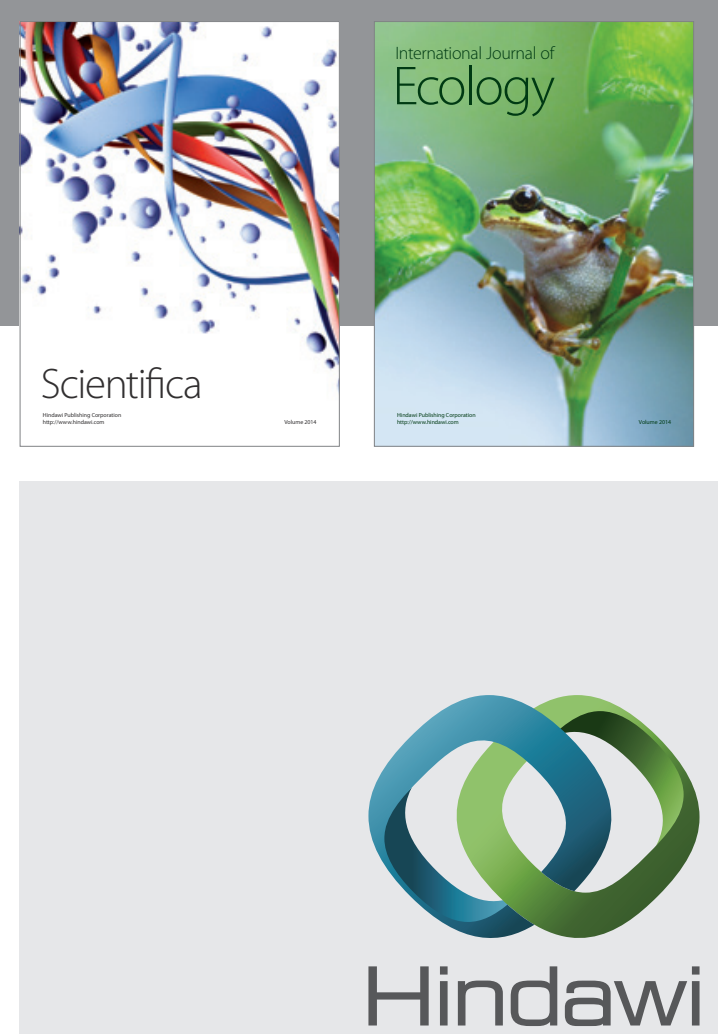

Submit your manuscripts at http://www.hindawi.com
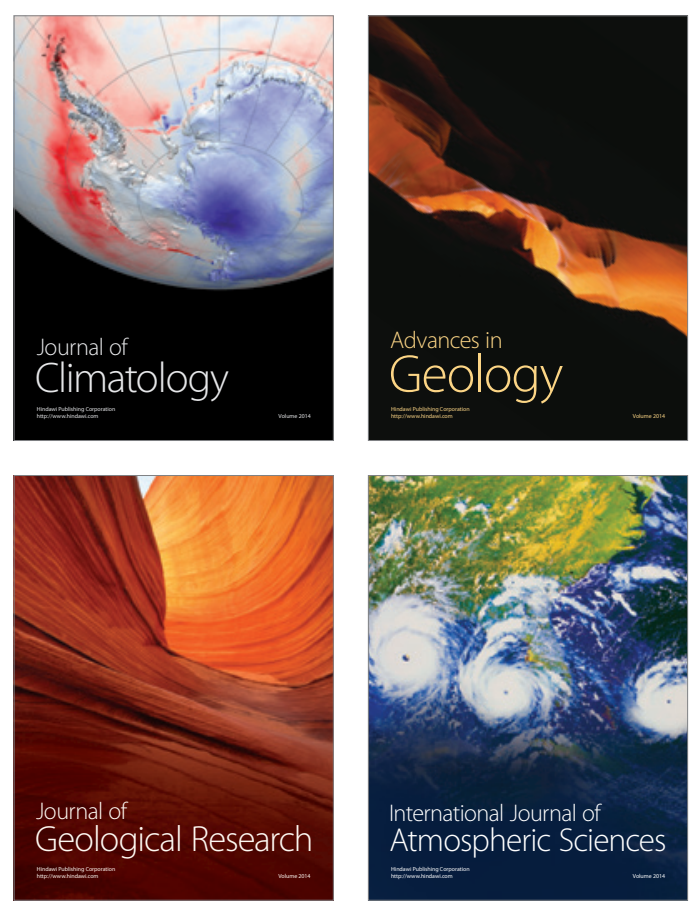
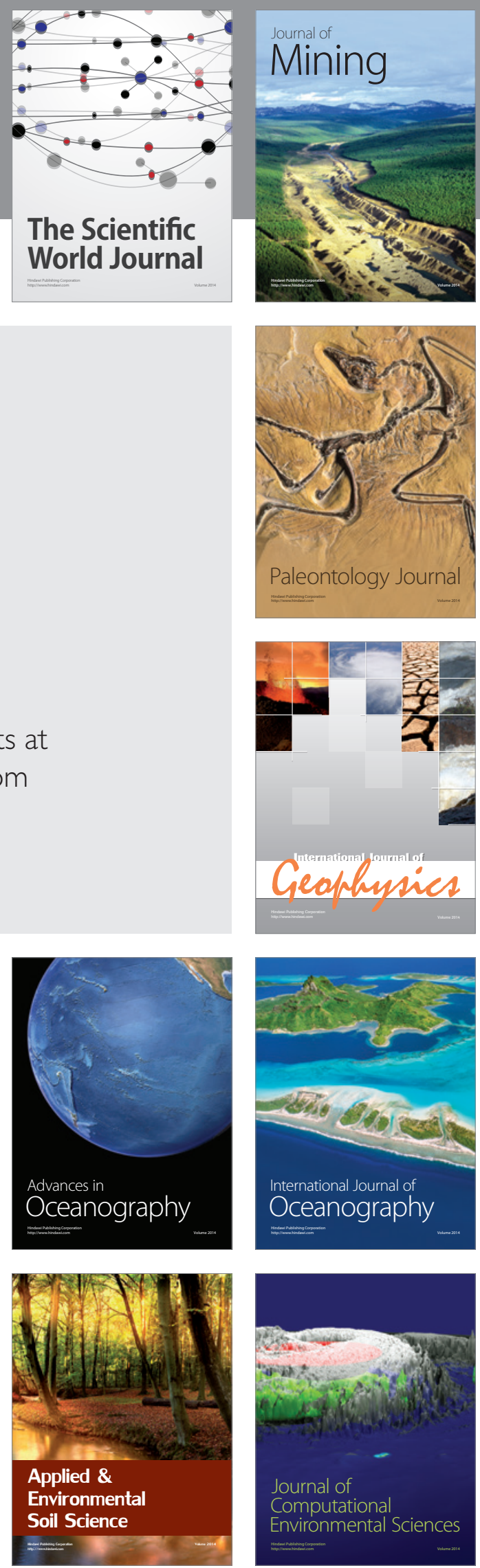